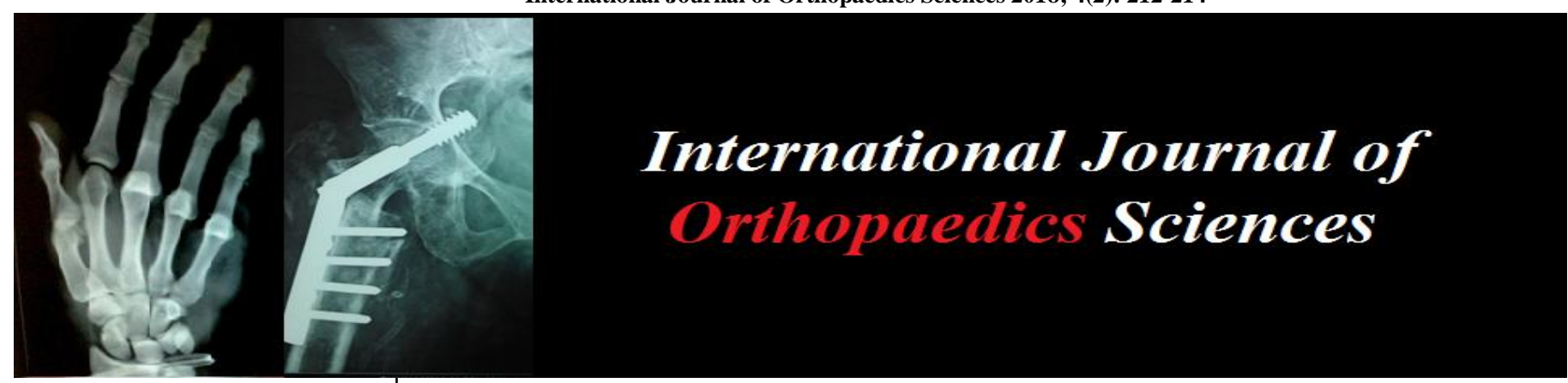

ISSN: $2395-1958$

IJOS 2018; 4(2): 212-214

(C) 2018 IJOS

www.orthopaper.com

Received: 01-02-2018

Accepted: 02-03-2018

Dr. Mirza Shahrukh Baig Senior Resident, Department of Orthopedics, Gandhi Medical

College and Hospital,

Hyderabad, Telangana, India

Dr. Srivanth Dasari

Senior Resident, Department of Orthopedics, Gandhi Medical

College and Hospital,

Hyderabad, Telangana, India

Dr. Raviteja Rudraraju

Senior Resident, Department of

Orthopedics, Gandhi Medical

College and Hospital,

Hyderabad, Telangana, India

Dr. Anoop Nippuleti

Senior Resident, Department of

Orthopedics, Gandhi Medical

College and Hospital,

Hyderabad, Telangana, India

Correspondence

Dr. Mirza Shahrukh Baig

Senior Resident, Department of

Orthopedics, Gandhi Medical

College and Hospital,

Hyderabad, Telangana, India

\section{Clinical profile of patients with distal humerus intercondylar fractures}

\author{
Dr. Mirza Shahrukh Baig, Dr. Srivanth Dasari, Dr. Raviteja Rudraraju, \\ and Dr. Anoop Nippuleti
}

DOI: https://doi.org/10.22271/ortho.2018.v4.i2d.31

\section{Abstract}

Inter-condylar fracture of the distal humerus is uncommon injuries and is difficult and challenging fracture for treatment. Restoration of the articular surface of distal humerus must be nearly perfect and sufficiently rigid to permit early mobilization of the elbow if the results is to be satisfactory. This was a prospective study of 20 cases of intercondylar fracture of distal

humerus in adults admitted to medial trust hospital. In our series of 20 cases, there were 9 males and 11 females with average of 44.1 years. 9 cases were due to direct fall and 11 road traffic accident, with predominance of left side (11). Out of 20 cases 5 (25\%) were of RR type II, 12 $(60 \%)$ were of RR III and $3(15 \%)$ were of RR IV.

Keywords: intercondylar; fracture; orif; humerus

\section{Introduction}

Inter-condylar fractures in adults are challenging to treat and require careful judgement and skill on the part of a surgeon. It may be impossible to secure any degree of accuracy in reduction by manipulation alone; and operative reduction and internal fixation presents considerable problems of surgical technique. In the young adult, it is important to obtain as near an anatomical reduction of the articular surfaces as possible. In the elderly patient with an excessively comminuted fracture in osteoporotic bone, fixation is often poor. It must be emphasized that any method of treatment that requires prolonged immobilization is likely to result in fibrosis and ankylosis of the joint ${ }^{[1]}$.

Prior to 1960, the consensus favoured non-operative management because of poor operative results. Since the advent of modern implants and surgical techniques permitting rigid internal fixation and early motion, recent publications favour operative management ${ }^{[2]}$.

The various methods of treatment are defended vigorously by their proponents. The most ardent are adherent of closed reduction; Watson-Jones doubted if results of internal fixation can ever be better than that of closed reduction. He said internal fixation is a difficult operation not to be taken lightly - "Anyone who has operated upon these badly broken and comminuted fractures of the lower end of the humerus must have been impressed by the extreme difficulty in fixing the fragments in their proper position". He stated that there can be little doubt that the worst treatment of comminuted inter-condylar fractures of the humerus is extensive operative reduction with internal fixation by triradiate plates, and many screws. Such operations by stripping the blood supply of the partly detached fragments and causing adhesion of muscles to bone cause serious stiffness. He was also of the opinion that since it is a flexion injury with forward displacement, it should not be immobilized in acute flexion. Even right-angled position is not entirely safe. He advised manipulation and immobilization in a plaster slab in the mid-flexed position as the safest conservative measure. The plaster slab is discarded in 2-3 weeks and the joint mobilized by the patient's own activity ${ }^{[3,4]}$.

In 1937 Eastwood, advocated the original Hugh Owen Thomas method, where the fracture is manipulated and wrist is suspended from the neck by a collar and cuff sling with the elbow at right angles allowing gravity and the weight of the limb to maintain the traction on the fragments - "Bag of Bones" technique. 
Brown and Morgan in 1941 reviewed the results of this method and reported an average of 70 degrees of motion. It is also significant that in the X-rays presented by both Eastwood and Morgan, good reduction of the fractures were noted. It has also been reviewed by Watson-Jones, Bickel and Perry and Evans and the consensus opinion is that the bag of bones technique is suitable for elderly patients in whom early ambulation is required ${ }^{[5]}$.

\section{Methodology}

The present is a prospective study includes 20 cases of intercondylar fracture of distal humerus admitted in medical trust hospital. The collected data was evaluated using appropriate statistical methods

- $\quad$ All adult patients with distal humerus fractures who were willing for surgery, and admitted during the period of study.

- Patients were Clinically and radiologically evaluated preoperatively and post-operatively

- The patients were assessed with the help of Riseborough and radin grading system post-operatively

- Laboratory investigations was carried out.

- Informed written consent of the patient was taken for surgical management.

\section{Inclusion criteria}

- Inclusion criteria

- Patients with intercondylar fracture of the distal end of the humerus (RR type1,2,3,4)

- Patients above the age of 18 years

- Patients medically fit for surgery.

\section{Exclusion criteria}

- Old fractures of the distal humerus

- Patients not willing for surgery

- Patients medically unfit for surgery.

\section{Results}

Table 1: Age distribution

\begin{tabular}{|c|c|c|}
\hline Age in years & No. of cases & Percentage \\
\hline $20-30$ & 5 & $25.0 \%$ \\
\hline $31-40$ & 5 & $25.0 \%$ \\
\hline $41-50$ & 4 & $20.0 \%$ \\
\hline $51-60$ & 2 & $10.0 \%$ \\
\hline $61-70$ & 3 & $15.0 \%$ \\
\hline $71-80$ & 1 & $5.0 \%$ \\
\hline \multicolumn{2}{|c}{} \\
\hline
\end{tabular}

In our study fractures were commoner in the fourth and fifth decade with average age being 44.1 years (20yrs-80yrs).

Table 2: Sex distribution

\begin{tabular}{|c|c|c|}
\hline Sex & No. of cases & Percentage \\
\hline male & 9 & $45 \%$ \\
\hline female & 11 & $55 \%$ \\
\hline
\end{tabular}

Our series had a female predominance with 55\%female (11) and $45 \%$ male (9) patients.

Table 3: Side involvement

\begin{tabular}{|c|c|c|}
\hline side involvement & no. of cases & percentage \\
\hline right & 9 & $45 \%$ \\
\hline left & 11 & $55 \%$ \\
\hline
\end{tabular}

We accounted about $45 \%$ incidence of fractures in right side (9) and 55\% (11) of the fracture in left side.

Table 4: Mode of injury

\begin{tabular}{|c|c|c|}
\hline Mode of injury & No. of cases & Percentage \\
\hline rta & 11 & $55 \%$ \\
\hline fall & 9 & $45 \%$ \\
\hline
\end{tabular}

In our series $45 \%$ (9) of the cases were due to direct fall and $55 \%$ (11) of cases had road traffic accident.

Table 5: Type of fracture (risenboroughradin classification)

\begin{tabular}{|c|c|c|}
\hline Typeoffracture & No. of cases & Percentage \\
\hline Type 1 & 0 & $0 \%$ \\
\hline Type 2 & 5 & $25 \%$ \\
\hline Type 3 & 12 & $60 \%$ \\
\hline Type 4 & 3 & $15 \%$ \\
\hline
\end{tabular}

In our series we had no cases of RR type I fractures (0), $25 \%$ fractures of RR type II (5), $60 \%$ fractures of RR type III (12) and $15 \%$ fractures of RR type IV (3).

Table 6: Associated injuries

\begin{tabular}{|c|c|c|}
\hline Associated Injuries & No. of cases & Percentage \\
\hline polytrauma & 1 & $5 \%$ \\
\hline distal radius & 2 & $10 \%$ \\
\hline femur & 2 & $10 \%$ \\
\hline ulna & 2 & $10 \%$ \\
\hline tibia & 1 & $5 \%$ \\
\hline none & 12 & $60 \%$ \\
\hline
\end{tabular}

Out of 20 patients 8 patients had associated injuries. one was poly trauma with chest injury and tibia fibula fracture, two had distal radius fractures, two had femur shaft fractures, two hadulna fractures and one had tibia fracture.

\section{Discussion}

In our study fractures were commoner in the fourth and fifth decade with average age being 44.1 years (20-80). Our findings are comparable to the study made by Jesse B. Jupiter 1985, Gabel et al 1987, M. Bradford Henley et al 1987, KunChuang Want et al., In 1985 Jesse B. Jupiter et al found 57 years as the average age in their series. In 1987 Gabel et al found 45 years as the average in their series. In $1987 \mathrm{M}$. Bradford Henley et al found 32 years as the average age in their series. In 1994 Kun-Chuang Want et al, found 47 years as the average age in their series ${ }^{[6,7]}$.

Our series had a female predominance with $55 \%$ and $45 \%$ male patient which were comparable to Jesse B. Jupiter et al, (1985). Jesse B. Jupiter et al, (1985) in his study noted about $47 \%$ male and $53 \%$ female, sex distribution. M. Bradford Henley et al in his study noted about $52 \%$ male and $48 \%$ female incidence. Kun-Chuang Wang et al, in his study noted $60 \%$ male and $40 \%$ female incidence.

In our series $45 \%$ of the cases were due to direct fall and $55 \%$ of cases had road traffic accident. Gabel et al accounted $100 \%$ of his cases to direct fall. M. Bradford Henley accounted $61 \%$ of his cases to road traffic accident, $39 \%$ due to direct fall. Kun-Chuang Wang, et al, accounted $30 \%$ of the cases to direct fall and $70 \%$ of the cases to road traffic accident. The results of the M. Bradford Henley et al, 1987 are comparable with our series $[8,9,10]$

We accounted about $45 \%$ incidence of fractures in right side and $55 \%$ of the fracture in left side, which is also comparable to other studies. Jesse B. Jupiter reported about $62 \%$ 
incidence of fractures in left distal end of humerus. $M$. Broadford Henley et al reported about 55\% incidence of fractures in left distal end of humerus. Left sided predominance is probable due to direct fall injury over left elbow which is common in our series.

\section{Conclusion}

Inter condylar fractures of the distal humerus are commoner in fourth and fifth decade of life with male predominant in high incidence of fracture due to outdoor activity.

- The mode of injury was direct fall on elbow or RTA.

- Inter condylar fractures demands careful evaluation, classification of fracture type and preoperative planning.

\section{References}

1. Bickel WF, Perry RE. Comminuted fractures of the distal humerus. JAMA. 1963; 181:553-557

2. Gerard TGl, Gregory H, James BB. Intraarticular fractures of the distal humerus in the adult. Clin Orthop\& Related Research. 1987; 216:99-108.

3. Kun CW, Hsin NS, Kuo-Yao H. Intercondylar fractures of the distal humerus: routine anterior subcutaneous transposition of the ulnar nerve in a posterior operative approach. J Trauma. 1994; 36(6):770-773.

4. Gupta R, Khanchandani P. Intercondylar fracture of the distal humerus in adults. Injury. 2002; 33(6):511-515.

5. Allende CA, Allende BT, Allende BL, Bitar I, Gonzalez G. Inter-condylar distal humrusfractures - Surgical treatment and results. Chir-Main. 2004; 23(2):85-95.

6. Helfet DL, Hotchkiss RN. Internal fixation of the distal humerus: A biomechanical comparison of methods. J Orthop Trauma. 1990; 4:260-264.

7. Riseborough EJ, Radin EL. Intercondylar T fractures of the humerus in the adult. A comparison of operative and non-operative treatment in twenty nine cases. J Bone Joint Surg. 1969; 51A: 130-141.

8. Schuster I, Korner J, Arzdorf $\mathrm{M}$ et al. Mechanical comparison in cadaverspecimens of three different 90degree double-plate osteosynthesesfor simulated C2-type distal humerus fractures with varying bonedensities. J Orthop Trauma. 2008; 22:113-120,

9. Muller ME, Allgower M, Schneider R, Willenegger $H$. Fracture of distal humerus. Chapter-7, In Manual of internal fixation, 3rd Edn. Springer-Verlag, 1995, 446452.

10. Jesse BJ. Complex fractures of the distal part of the humerus and associated complications. J Bone Joint Surg Am. 1994; 76:1253-1264. 